\title{
Operational Modal Analysis for Crack Detection in Rotating Blades
}

\author{
Jarosław BEDNARZ \\ Department of Robotics and Mechatronics, AGH University of Science and Technology \\ al. Mickiewicza 30, 30-059 Kraków, Poland; e-mail: bednarz@agh.edu.pl
}

(received April 27, 2016; accepted November 24, 2016)

\begin{abstract}
Vibration analysis has found widespread application for condition monitoring in a variety of applications and industries. With the continual development of cheaper and more powerful processing hardware, such systems have developed from utilizing simple checks on amplitude to those based around sophisticated spectral analysis. The paper presents application of the model based diagnostic method for early detection of faults in rotating machinery. The proposed diagnostics system based on modal analysis methods (OMA and OMAX methods). In the paper the diagnostic system based on such modelling is presented. The proposed system was verified during research on a specialized test rig, which can generate vibration signals.
\end{abstract}

Keywords: Operational Modal Analysis; rotor dynamics; blade crack diagnostics.

\section{Introduction}

In the last few years, for the purposes of identification of mechanical systems during their normal work the OMA (Operational Modal Analysis) methods have been frequently used (HeRmAns et al., 1996; UHL et al., 2001). These methods can be applied under the assumption that the excitation acting on the tested system is random. This requirement is not met in case of some industrial machines (e.g. in power engineering) while the excitation related to rotating elements significantly worsen the accuracy of modal models estimated by means of the OMA methods (KuRowsKI, 2007). Therefore the methods making it possible to overcome this problem arise great interest. One of such methods is OMAX (Operational Modal Analysis with eXternal Inputs) that nowadays has been more and more frequently applied to operational identification of mechanical structures (BEDNARZ et al., 2005; HERMANS et al., 1997; HEYLEN et al., 1993). The paper concerns comparison of the classical methods (OMA) and OMAX method. The results were verified experimentally for the characteristics measured on the laboratory object.

\section{Fundamentals of OMAX}

The OMAX (Operational Modal Analysis with eXogenous Inputs) (CAUBERGHe, 2004) method is for- mulated with an assumption that both measurable and immeasurable forces excite structure vibrations. Therefore, in the method the response is considered as consisting of two components: one is deterministic excited by the measurable forces and second - stochastic excited by immeasurable forces (Fig. 1).

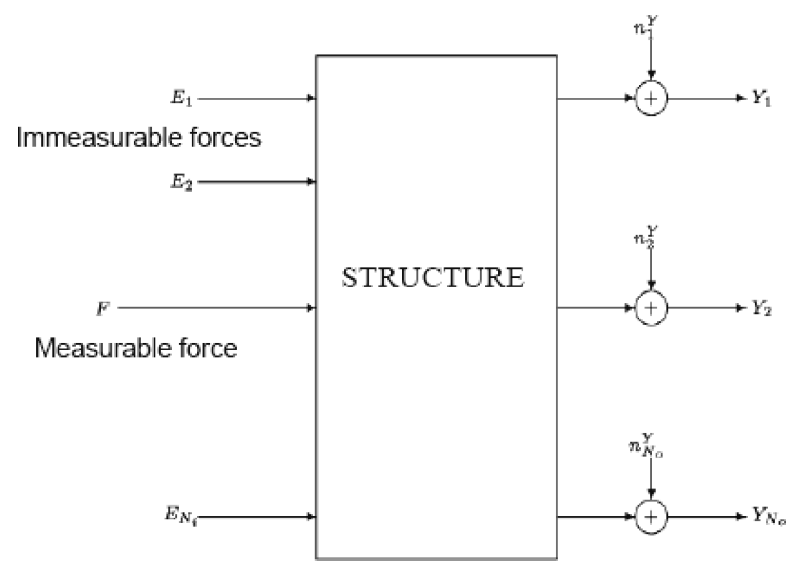

Fig. 1. Scheme of experimentally and operationally loaded structure.

To consider the response the following equation of system dynamics in a form of discrete time can be considered:

$$
\begin{aligned}
z_{k} \mathbf{X}_{k} & =\mathbf{A} \mathbf{X}_{k}+\mathbf{B} \mathbf{F}_{k}+\mathbf{W}_{k}, \\
\mathbf{Y}_{k} & =\mathbf{C X}_{k}+\mathbf{D} \mathbf{F}_{k}+\mathbf{V}_{k},
\end{aligned}
$$


where $\mathbf{X}_{k}, \mathbf{Y}_{k}, \mathbf{F}_{k}$ - state, output and input vectors, $\mathbf{A}, \mathbf{B}, \mathbf{C}, \mathbf{D}$ - state, input, output and throughput matrices, $\mathbf{W}_{k}, \mathbf{V}_{k}$ - Gaussian noises.

For above state space equations the input - output relation can be written in the following form:

$$
\begin{aligned}
\mathbf{Y}_{k}= & {\left[\mathbf{C}\left(\mathbf{I} z_{k}-\mathbf{A}\right)^{-1} \mathbf{B}+\mathbf{D}\right] \mathbf{F}_{k} } \\
& +\mathbf{C}\left(\mathbf{I} z_{k}-\mathbf{A}\right)^{-1} \mathbf{W}_{k}+\mathbf{V}_{k} .
\end{aligned}
$$

The first term of formula describes influence of deterministic part on system output and the second oneof stochastic part. As a result, both deterministic and stochastic contributions contain information about the system dynamics, term $\left(\mathbf{I} z_{k}-\mathbf{A}\right)$. Based on this formulation several OMAX identification methods have been developed (CAuberghe et al., 2003; Chen, TomlinSon, 1994; Peeters, De Roeck, 2001). The most useful are common-denominator based method, LMFD (Left-Matrix Fraction Description) and frequency domain state space based method. In a linear case for estimation of modal parameters of the system these methods can be directly applied. To estimate modal parameters in OMAX method the following basic formula can be applied:

$$
\left[H^{m}\left(\omega_{k}\right) S_{y y}^{+}\left(\omega_{k}\right)\right]=\sum_{r=1}^{m}\left(\frac{\phi_{r} Q_{r}^{T}}{1-\lambda_{r} z_{k}^{-1}}+\frac{\phi_{r}^{*} Q_{r}^{T}}{1-\lambda_{r}^{*} z_{k}^{-1}}\right) .
$$

If experimental forces (deterministic part of OMAX method) and system total response are known, the system can be transformed to the following relation:

$$
\begin{aligned}
Y_{o, b}\left(\omega_{k}\right)= & \frac{B_{o i}\left(z_{k}\right)}{A\left(z_{k}\right)} F_{b}\left(\omega_{k}\right)+\frac{T_{o, b}\left(z_{k}\right)}{A\left(z_{k}\right)} \\
& +\frac{C_{o}\left(z_{k}\right)}{A\left(z_{k}\right)} E_{o, b}\left(\omega_{k}\right)
\end{aligned}
$$

where $Y$ and $F$ are DFT spectra of output and input signals, $E_{o, b}\left(\omega_{k}\right)$ - unknown Gaussian white noise (stochastic excitation), $B_{o i}\left(z_{k}\right)$ - numerator polynomial, $A\left(z_{k}\right)$ - common-denominator polynomial, $T_{o, b}\left(z_{k}\right)-$ the transient polynomial for output $o$.

In fact the transient polynomial $T_{o, b}\left(z_{k}\right)$ represents the non-steady state response of the system and in this way errors introduced by leakage are avoided. It can be easily noticed that each term of formula contains polynomial $A\left(z_{k}\right)$ which describes system dynamics, but in practical application at each term given system poles (roots of characteristic equations $A\left(z_{k}\right)=0$ ) are excited in different way. To obtain model parameters the model prediction error should be minimized, it leads to minimizing the following objective function (CLSF approach):

$$
l_{I O}^{\mathrm{CLSF}}(\Theta)=\sum_{o=1}^{N_{o}} \sum_{b=1}^{N_{b}} \sum_{k=1}^{N_{f}}\left|E_{o, b}\left(\omega_{k}\right)\right|^{2},
$$

where

$E_{o, b}\left(\omega_{k}\right)=\frac{B_{o i}\left(z_{k}\right) F_{b}\left(\omega_{k}\right)-A\left(z_{k}\right) Y_{o, b}\left(\omega_{k}\right)-T_{o, b}\left(z_{k}\right)}{C_{o}\left(z_{k}\right)}$.

During the estimation process numerical stability should be very carefully investigated (the problem with zeros of polynomial $C_{o}\left(z_{k}\right)$ (Pintelton, Schoukens, 2001). Similar approach can be formulated MLCF, LSCF for both FRF and IO data. The LSCF approaches are fastest, but give raw approximations in presence of high level noise, although MLCF method is more robust and can be used in cases of high noise level. For time varying case the formula can be rewritten in the form:

$$
\begin{aligned}
Y_{o, b}\left(\omega_{k}, i\right)= & \frac{B_{o i}\left(z_{k}, i\right)}{A\left(z_{k}, i\right)} F_{b}\left(\omega_{k}, i\right)+\frac{T_{o, b}\left(z_{k}, i\right)}{A\left(z_{k}, i\right)} \\
& +\frac{C_{o}\left(z_{k}, i\right)}{A\left(z_{k}, i\right)} E_{o, b}\left(\omega_{k}, i\right),
\end{aligned}
$$

where $i$ is discrete time index.

To identify system poles the recursive formula (UHL, BogACZ, 2004) can be applied and natural frequency and modal damping changes can be described.

\section{Laboratory test rig description}

The rotordynamics test rig (Fig. 2) was designed and installed in Department of Robotics and Mechatronics University of Science and Technology (AGH). Its main goal is research of diagnostic techniques for rotating machinery. Additionally it is used for other research work (e.g. Operational Modal Analysis).

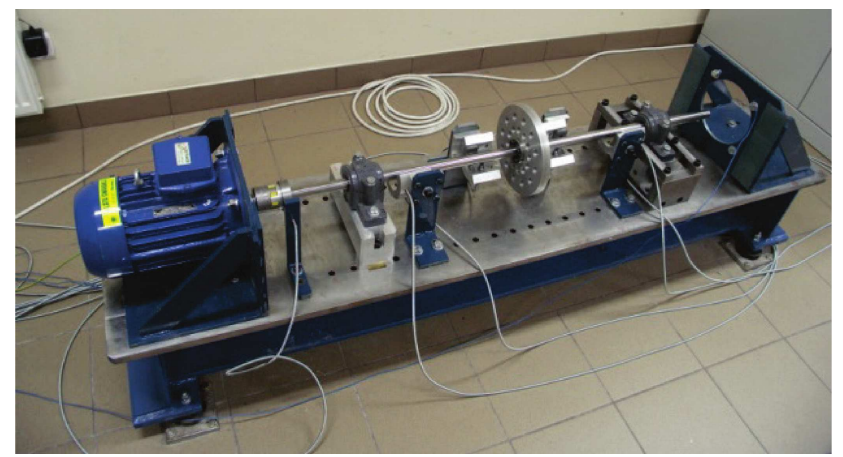

Fig. 2. Photograph of the rotordynamic research test rig.

The rotor - bearing system is mounted on the heavy steel plate. The rotor is driven by the $1.2 \mathrm{~kW}$ AC motor, controlled by the converter. The converter controls the rotational speed set manually or from a PC through a serial link. Various transient states can be easily tested. The driven system can consist of one $1200[\mathrm{~mm}]$ or two 600 [mm] rotors, mounted on bearings. The rig has exchangeable bearings, rolling and sliding ones. One of bearing supports can introduce controlled misalignment. Up to few disks can be 
mounted on rotors, to introduce static or dynamic unbalance. It is possible to introduce looseness and rotor rub. The rig is equipped with rotational speed controller and vibration measurement system.

One of the test-rig components stands the programmable vibration excitator together with the electromagnetic actuator (PIŁAT, 2002). The electromagnet is based on the $E$-shape core with the coil located at the centre pole. The pole face of the electromagnet is specially rounded with the radius $R_{e m}$ to maximize the performance and generated electromagnetic forces while acting on the shaft with diameter $d_{r}$ (see Fig. 3 for details).

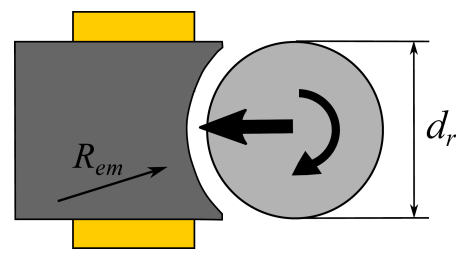

Fig. 3. Electromagnet.

The nominal force $300 \mathrm{~N}$ is obtained for the air gap between the rotor pole and shaft surface equal to $900 \mu \mathrm{m}$. The electromagnet is located at the mounting aluminum block containing magnetic chucks, which allows to position the electromagnet with the specified distance from the rotor surface. With this feature the electromagnetic force acting on the shaft can be changed by the distance modification. To control the electromagnetic force dedicated controller is used (Fig. 4) (PiŁAT, 2004).

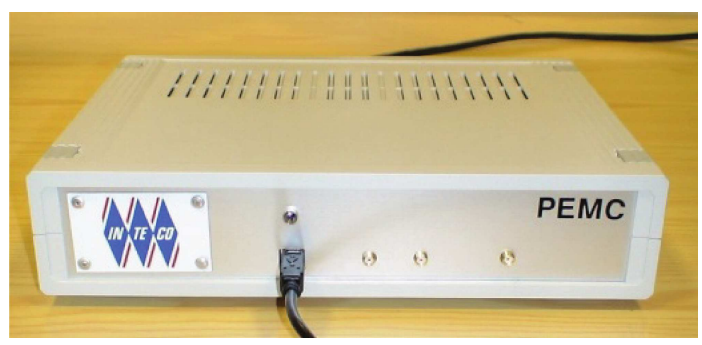

Fig. 4. General view of dedicated controller.

This device contains a power driver that controls the current in the coil and microprocessor based programmable electronics that allows to generate requested signal shapes. The controller allows to generate three types of signals:

1. Sine wave with the desired frequency, amplitude and offset.

2. Chirp signal defined by the starting and final frequency. The transition between frequencies is defined by the period of time. The amplitude and offset of the generated chirp signal can be also tuned.

3. User defined noise signal based on 256 samples. The user can create an individual signal defining a vector of 256 values in the specified range with offset.

The controller contains one extra feature for the external devices synchronisation. Plugging the noncontact shaft distance sensor to the controller the trigger level can be adjusted in the programmable way to generate digital pulses. One can imagine that the rotor has a hole which rotates under the sensor surface. Thus the strong distance change can be observed. The generated pulse can be used as:

1) rotation counter,

2) rotation synchronization signal.

The controller is connected to the host computer via USB interface to download program signal shapes. On the host computer the MATLAB based application is installed and allows to configure generated signals. The application can be individually configured to establish an unlimited number of scenarios for excitation experiments. The application window is presented in Fig. 5.

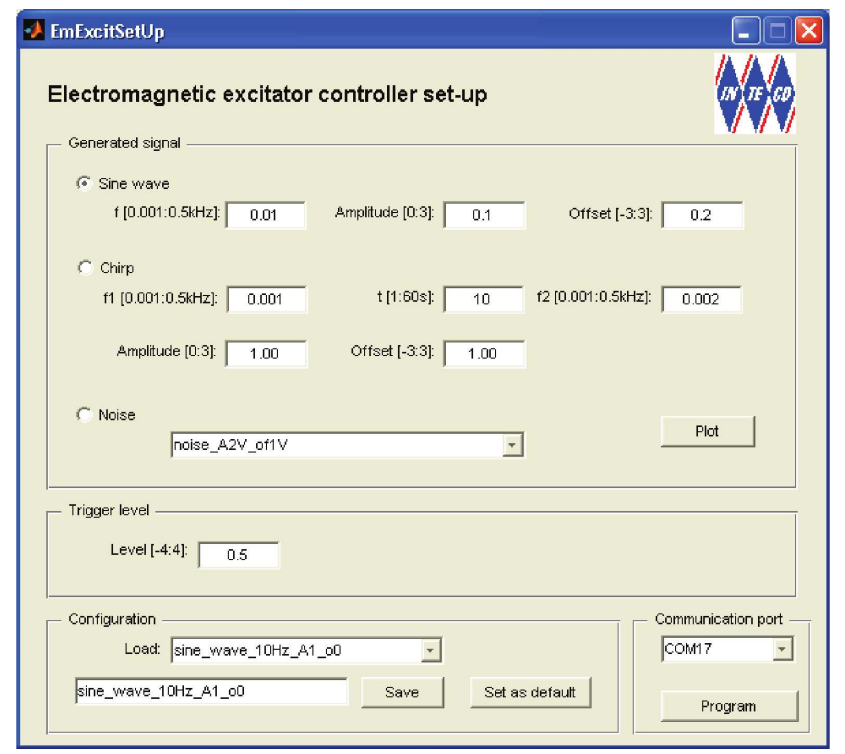

Fig. 5. Configuration panel.

The application is organized into four sections:

1) generated signal - user can select signal type and set-up its properties,

2) trigger level - availability to adjust trigger level for pulse generation,

3) configuration - load and save configuration for easy application handling,

4) communication - program button allows to download the configuration to the controller.

To check the possibility of using an active magnetic bearing as external excitation in OMAX method a number of investigations were realized. The coil current was applied in a form of sine-wave, chirp-wave and noise. To observe rotor deflections the proximity probe 
was installed at the opposed side. The excitation signal was applied to the electromagnet and the distance was measured (Fig. 6).

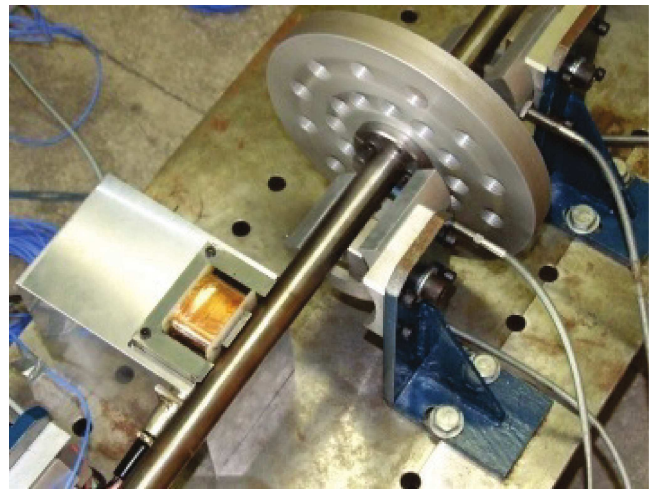

Fig. 6. Test rig with electromagnetic exciter.

\section{Experimental results}

Blade cracks are one of the most dangerous damage in rotating machinery (ORŁOWsKI, 2001; ŁĄCZKOWSKI, 1974) and numerous researches in this field were done (Chen, Mo, 2004; Smit, Heyns, 202; Stoisser, Audebert, 2008). This chapter concerns detection and identification of turbine blade cracking by means of the modal analysis method damage detection technique. The idea of using an electromagnetic exciter for blade crack detection in OMAX method is also presented. For the tests described in this chapter the test rig was modified by mounting the blades at the end of the shaft (Fig. 7). Then a crack of a blade was introduced (Fig. 8).

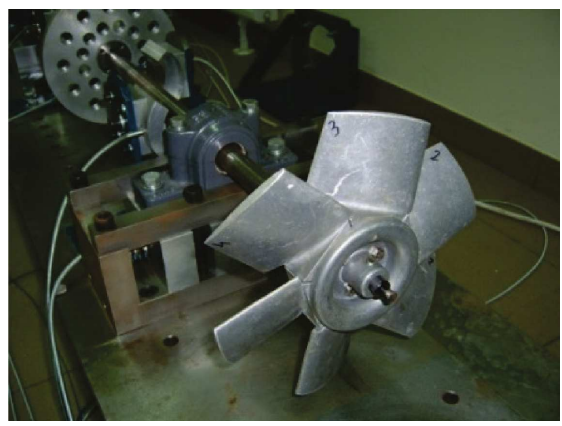

Fig. 7. Experimental rig with blades.

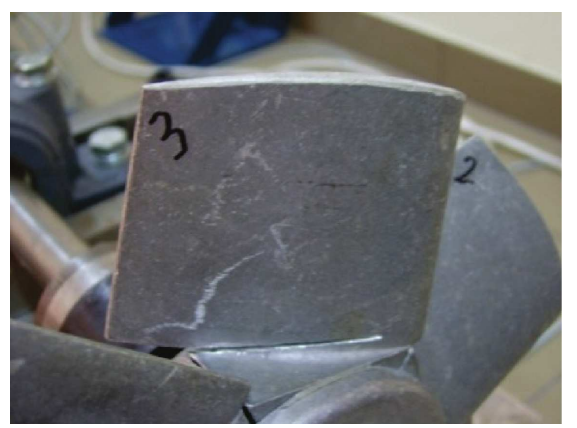

Fig. 8. Simulation of crack at blade no 3 .

\subsection{Analysis of rotating blades resonant frequencies}

In the first stage of experiment the modal parameters of blade with and without crack were estimated. The frequency response functions (FRFs) of damage and undamaged blade no. 3 are presented in Figs. 9 and 10 .

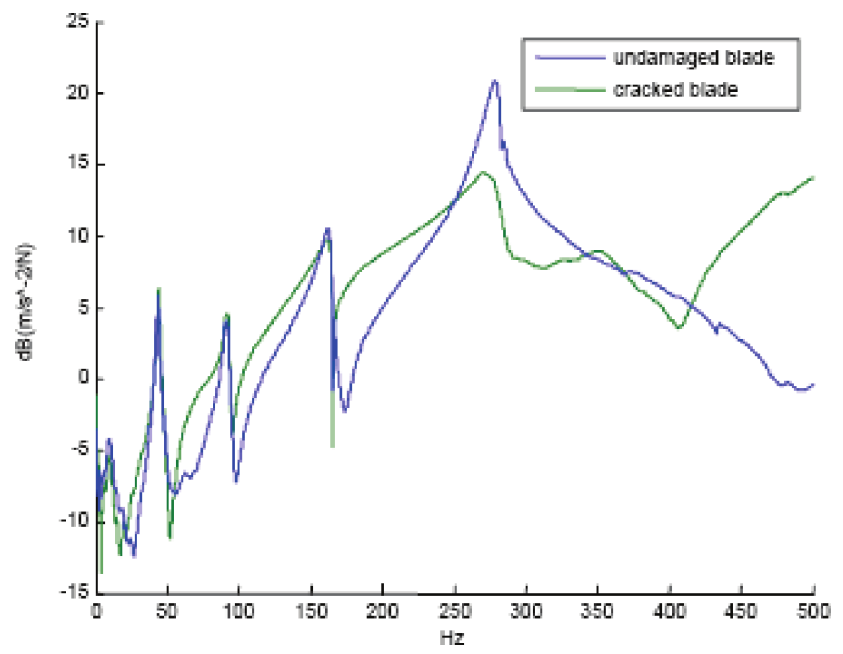

Fig. 9. FRFs of blade no. 3 .

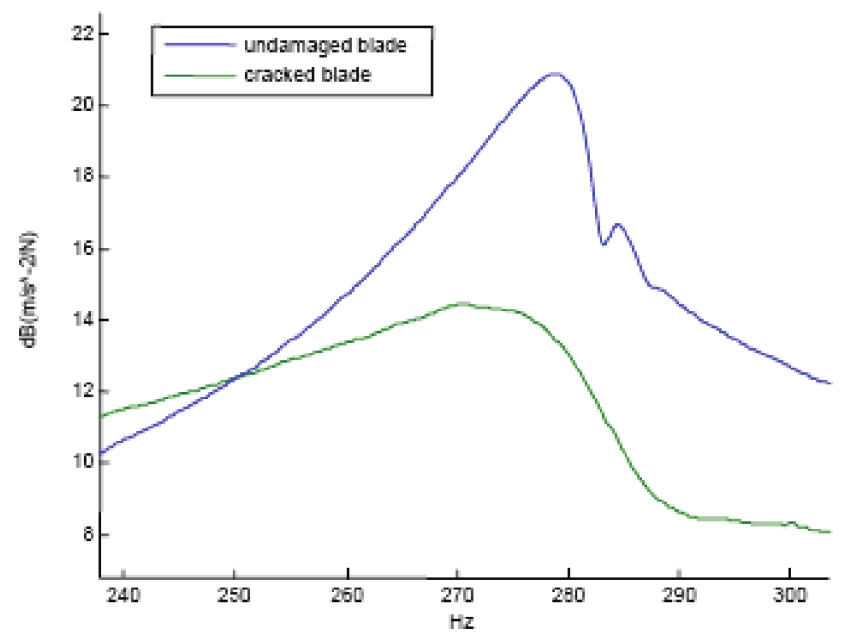

Fig. 10. FRFs of blade no. 3 (difference in 1st natural frequency).

During the experiment the influence of dismounting and mounting blades on their modal parameters (natural frequency and modal damping ratio) was also investigated. The results of these researches for blade no. 3 are presented in Fig. 11. In Fig. 12 the FRFs of every blade are presented. Analyses of the presented FRFs clearly show that mounting and dismounting blades has no influence on their natural frequencies. 


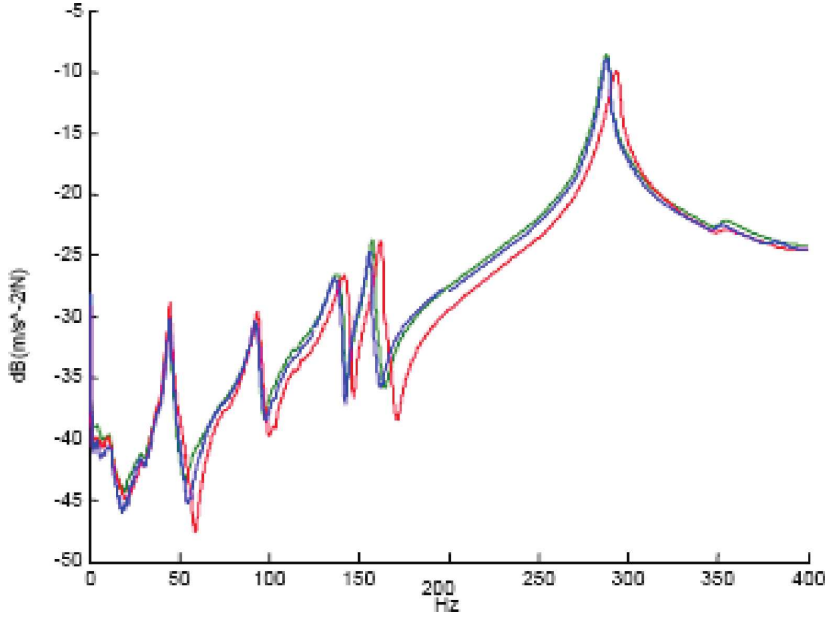

Fig. 11. FRFs of blade no. 3 .

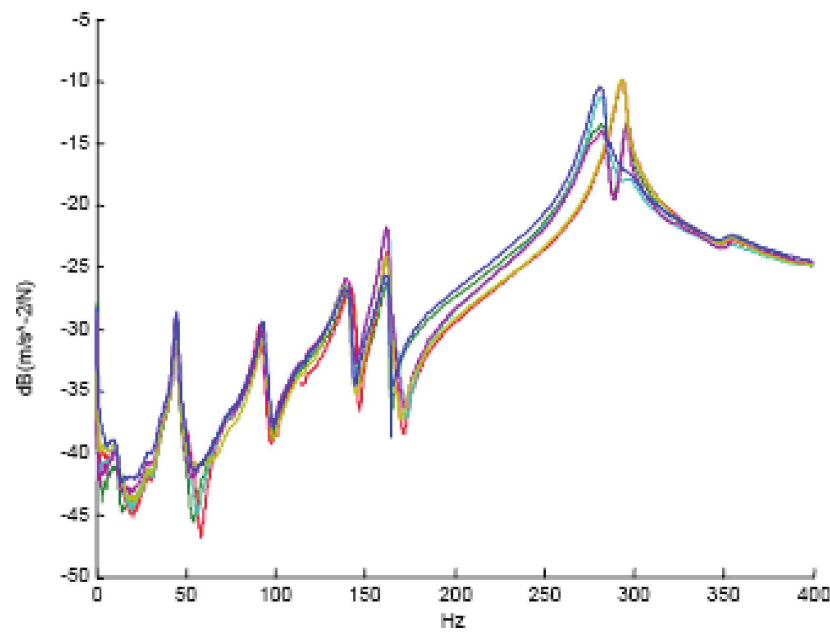

Fig. 12. FRFs of every blade.

Table 1. Modal parameters of investigated object.

\begin{tabular}{|c|c|c|c|c|c|c|c|c|}
\hline \multirow[b]{3}{*}{ No } & \multicolumn{4}{|c|}{ OMA } & \multicolumn{4}{|c|}{ OMAX } \\
\hline & \multicolumn{2}{|c|}{ Blade without crack } & \multicolumn{2}{|c|}{ Blade with crack } & \multicolumn{2}{|c|}{ Blade without crack } & \multicolumn{2}{|c|}{ Blade with crack } \\
\hline & $\begin{array}{c}\text { Natural } \\
\text { frequency } \\
{[\mathrm{Hz}]} \\
\end{array}$ & $\begin{array}{c}\text { Modal } \\
\text { damping ratio } \\
{[\%]}\end{array}$ & $\begin{array}{c}\text { Natural } \\
\text { frequency } \\
{[\mathrm{Hz}]}\end{array}$ & $\begin{array}{c}\text { Modal } \\
\text { damping ratio } \\
{[\%]}\end{array}$ & $\begin{array}{c}\text { Natural } \\
\text { frequency } \\
{[\mathrm{Hz}]} \\
\end{array}$ & $\begin{array}{c}\text { Modal } \\
\text { damping ratio } \\
{[\%]}\end{array}$ & $\begin{array}{c}\text { Natural } \\
\text { frequency } \\
{[\mathrm{Hz}]} \\
\end{array}$ & $\begin{array}{c}\text { Modal } \\
\text { damping ratio } \\
{[\%]}\end{array}$ \\
\hline \multicolumn{9}{|c|}{ Results for accelerometers } \\
\hline 1 & 86.26 & 0.71 & 86.26 & 0.63 & 86.35 & 1.04 & - & - \\
\hline 2 & - & - & - & - & - & - & 120.68 & 6.38 \\
\hline 3 & 215.80 & 0.31 & 215.95 & 0.29 & 215.85 & 0.34 & 215.52 & 0.59 \\
\hline 4 & - & - & 252.72 & 0.06 & - & - & - & - \\
\hline \multicolumn{9}{|c|}{ Results for eddy-current sensors } \\
\hline 1 & 28.83 & 0.40 & 28.84 & 0.49 & 28.95 & 0.13 & 28.9924 & 0.20 \\
\hline 2 & 34.49 & 0.95 & - & - & - & - & - & - \\
\hline 3 & 39.28 & 0.51 & - & - & - & - & - & - \\
\hline 4 & 42.63 & 0.68 & 42.96 & 1.13 & 42.98 & 1.32 & 42.4613 & 2.09 \\
\hline 5 & 44.29 & 0.09 & - & - & - & - & 43.3696 & 1.27 \\
\hline 6 & 86.70 & 0.22 & 86.92 & 0.52 & 86.91 & 0.26 & 86.9149 & 0.26 \\
\hline 7 & 91.60 & 1.80 & - & - & - & - & - & - \\
\hline 8 & - & - & - & - & 102.20 & 0.25 & 102.1128 & 0.19 \\
\hline 9 & 116.00 & 0.46 & 115.97 & 0.19 & 115.95 & 0.27 & 115.9663 & 0.29 \\
\hline 10 & 144.56 & 0.26 & 144.59 & 0.05 & 144.69 & 0.20 & - & - \\
\hline 11 & 173.39 & 0.14 & - & - & 173.53 & 0.17 & - & - \\
\hline 12 & - & - & - & - & 186.81 & 0.70 & 186.7555 & 0.71 \\
\hline 13 & - & - & - & - & 202.69 & 0.26 & - & - \\
\hline
\end{tabular}

After these researches the OMA and OMAX sensitivity to blade crack detection was examined. The OMA and OMAX method was applied to crack detection of the blade number 3. Natural frequencies and modal damping ratio of a test rig were calculated by means of the BR algorithm. Electromagnetic exciter was used as an external excitation in OMAX method. The experimental results are presented in Table 1.

The results of experiment clearly show that $\mathrm{OMA}(\mathrm{X})$ can be successfully used for blade crack de- tection. The better results can be obtained by using the eddy-current displacement sensors than the accelerometers.

\subsection{OMAX results with application of electromagnetic exciter}

Using of the electromagnetic exciter for blade crack detection was investigated. Diagnostics algorithm based on excitation of blades vibrations during 
the normal work of test rig with using the electromagnetic exciter (excitation signal - sinus with frequency of 1st natural frequency of blades). The experiment was carried out as follow:

1) estimation of 1st natural frequency of blades,

2) excitation the vibrations of blades during the normal work of test rig with using the electromagnetic exciter (excitation signal - sinus with frequency of 1st natural frequency of blades),

3) measurement of vibration accelerations on bearing covers,

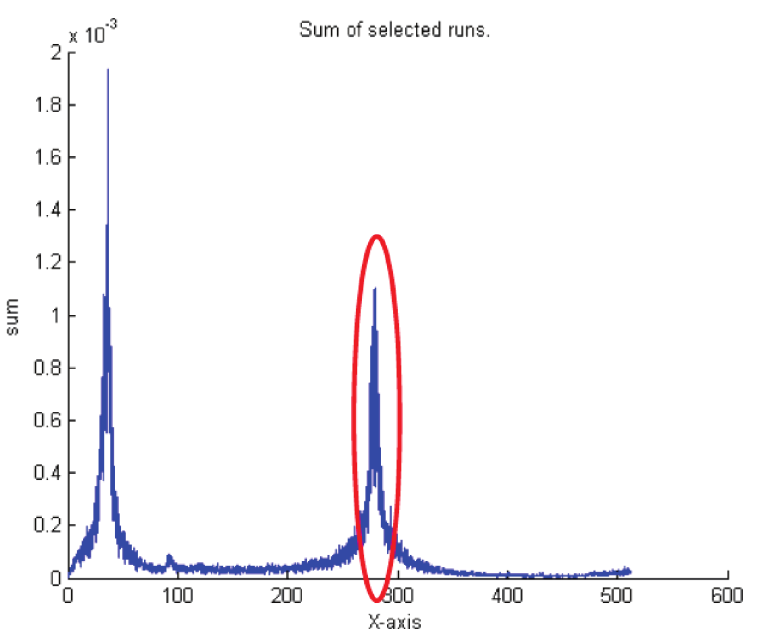

Fig. 13. FRF of damaged blade.
4) estimation of modal parameters of investigated object.

The FRFs recorded at blade and bearing covers are presented in Figs. 13 and 14.

Analysis of these FRFs clearly shows that using of electromagnetic exciter allows to excite the 1st natural frequency of investigated blades and measure it by accelerometer placed on bearing cover. Experiment results evidently demonstrate that introducing a crack on one of the blades caused the changes in natural frequencies of investigated object (Table 2). These

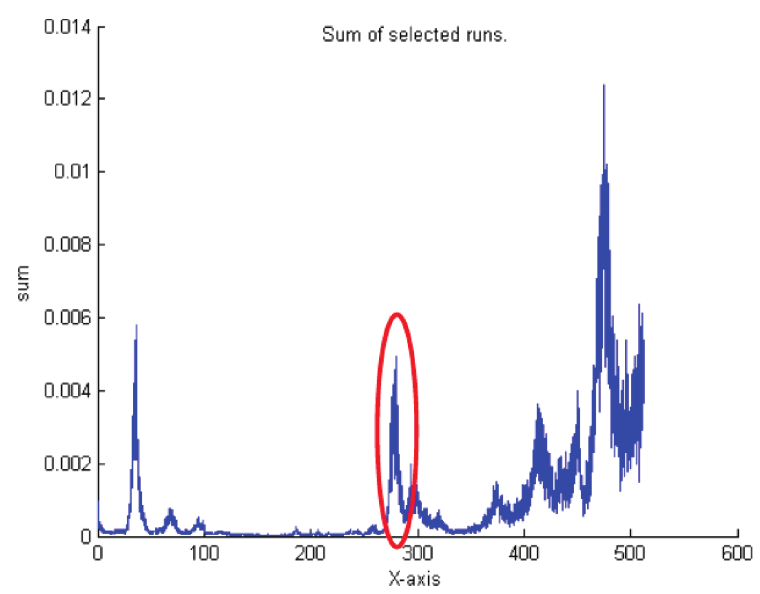

Fig. 14. FRF recorded by accelerometers placed on bearing cover.

Table 2. Modal parameters of investigated object.

\begin{tabular}{|r|c|c|c|c|}
\hline \multirow{2}{*}{ No } & \multicolumn{2}{|c|}{ Blade with crack } & \multicolumn{2}{c|}{ Blade without crack } \\
\cline { 2 - 5 } & Natural frequency [Hz] & Modal damping ratio [\%] & Natural frequency [Hz] & Modal damping ratio [\%] \\
\hline 1 & 31.82 & 0.02 & 31.79 & 0.08 \\
\hline 2 & 35.90 & 0.13 & - & - \\
\hline 3 & 40.16 & 0.26 & - & - \\
\hline 4 & 45.59 & 0.92 & 49.95 & 0.93 \\
\hline 5 & 50.09 & 0.46 & 63.76 & 0.01 \\
\hline 6 & 63.78 & 0.02 & 95.82 & 0.10 \\
\hline 7 & 96.04 & 0.83 & 99.90 & 0.23 \\
\hline 8 & - & - & 126.69 & 0.17 \\
\hline 9 & - & - & 151.74 & 0.29 \\
\hline 10 & 156.79 & 1.82 & 166.94 & 0.65 \\
\hline 11 & - & - & 181.44 & 0.96 \\
\hline 12 & - & - & 184.57 & 0.30 \\
\hline 13 & 184.30 & 0.33 & 191.56 & 0.06 \\
\hline 14 & - & - & 216.84 & 0.02 \\
\hline 15 & - & - & 223.33 & 0.27 \\
\hline 16 & 224.86 & 0.67 & - & - \\
\hline 17 & 256.35 & 0.99 & $\mathbf{2 8 6 . 5 4}$ & $\mathbf{0 . 7 7}$ \\
\hline 18 & $\mathbf{2 8 0 . 1 6}$ & $\mathbf{0 . 9 0}$ & - & - \\
\hline 19 & 292.17 & 1.47 & - & - \\
\hline 20 & 311.60 & 0.92 & & - \\
\hline
\end{tabular}


changes appear near the frequency of $280[\mathrm{~Hz}]$ - the 1st natural frequency of blades. The value of 1st natural frequency of blades decreases about 3 [\%] (about $7[\mathrm{~Hz}])$. This change of 1st natural frequency of blades shows that one of blade has failure and this change can be used as diagnostics symptom in blade crack detection algorithm.

\subsection{Proposed diagnostics algorithm}

The main purpose of the researches was to find a best diagnostics algorithm which can allow detection of blade cracking. The proposed algorithm is based on modal model and is shown in Fig. 15. The first stage of proposed diagnostics algorithm is the estimation of modal parameters (natural frequencies, modal damping ratios and mode shapes) of the investigated object with set of undamaged blades. The modal model can be obtained by means of Experimental Modal Analysis or OMA method. There is possibility to estimate modal parameters during a normal operation of machines (in OMAX approach) without any unnecessary stage-downs. This experiment can be done after the major repair of investigated object.

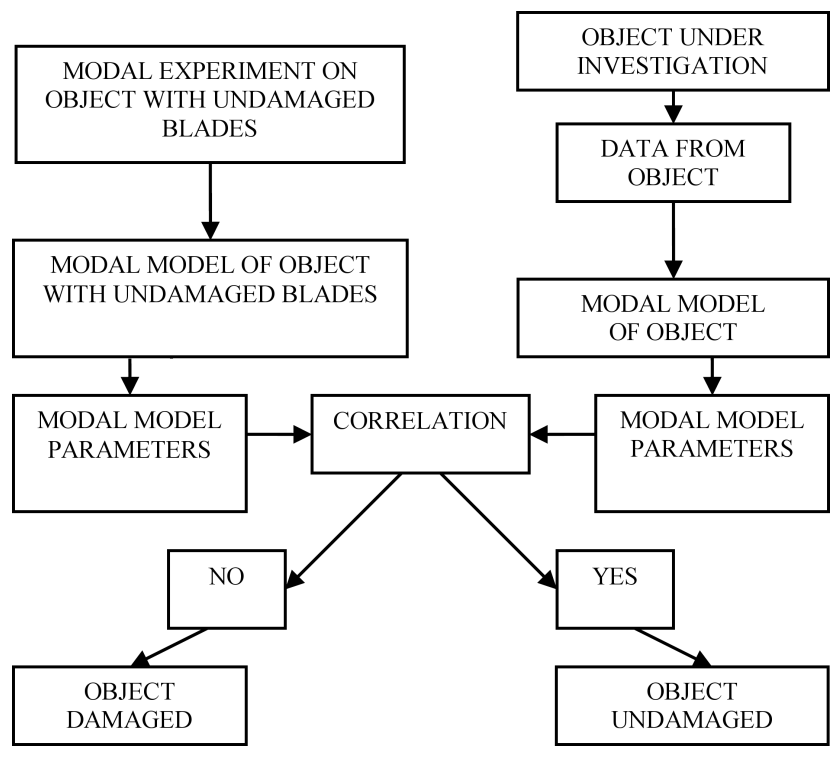

Fig. 15. Scheme of proposed diagnostics algorithm.

During the normal work of monitored object the active experiment is being done periodically with the same excitation as in the experiment on undamaged object. For data obtained during this experiment the modal parameters estimation is being done. These parameters are compared with the modal parameters obtained for the object in the initially state. If the correlation between these two sets of modal parameters is close to one the object is undamaged. If the correlation between these two sets of modal parameters has low value (near zero) a failure in object might be expected.

\section{Conclusion}

The objective of this paper has been realized by formulation of diagnostics algorithms based on modal analysis techniques and nonlinear parametric models of vibration signals. The proposed algorithms were experimentally verified during the tests on laboratory test stand and on data collected in wind power plant.

The main original contributions in this work can be summarized as follows:

1) the formulation of diagnostics methods and algorithms for rotating machinery based on modal analysis techniques,

2) implementation of the OMAX method for nonlinear cases,

3) the use of active magnetic bearing as measurable external excitation in the OMAX method during the normal operation of investigated machine,

4) the use of active magnetic bearing in blade cracks detection,

5) experimental verification of proposed diagnostic methods on laboratory test stand.

Experimental results clearly show that modal analysis techniques can be successfully implemented in rotating machinery diagnostics. On-line monitoring systems can base on $\mathrm{OMA}(\mathrm{X})$ method. In OMAX case one can use as external excitation an electromagnetic device such as active magnetic bearing.

One of the most important advantages of these methods is possibility to use them in on-line blade crack detection. Cracked blade can cause a catastrophically failures in turbo machinery so it is very important to find the crack in early stage. Proposed algorithm based on OMAX method allows to check every blade separately and significantly increase the safety of turbine.

The big advantage of these methods is possibility to use them for planning of routine and major repairs. In OMAX method differences in natural frequencies and damping ratios increase according to damage growing. This means that there is possibility to calculate estimated time for normal operation of machine. Proposed in the paper approach to damage detection and structural health monitoring decreases the cost of rotating machinery operating. There is a possibility to do a diagnostics experiment during a normal operation of machines (in OMAX approach) without any unnecessary stage-downs. Presented results proved applicability and advantages of $\mathrm{OMA}(\mathrm{X})$ method in model based structural health monitoring of rotating machinery. However, it should be noticed that the presented methods are complicated in application for nonlinear systems or systems with parameters varying over time. 


\section{References}

1. Bednarz J., Barszcz T., Uhl T. (2005), Dynamic condition analysis of rotating machinery - a laboratory case study [in Polish], Selected problems of modal analysis of mechanical systems. Publishing House of the Institute for Sustainable Technologies - National Research Institute, Radom, Poland, pp. 144-150.

2. Cauberghe B. (2004), Applied frequency-domain system identification in the field of experimental and operational modal analysis, Ph.D. Thesis, VUB, Brussel.

3. Cauberghe B., Guillaume P., Verboven P., ParLOO E. (2003), Identification of modal parameters in presence of unmeasured forces and transient effects, Journal of Sound and Vibration, 265, 609-625.

4. Chen CH., Mо CH. (2004), A method for intelligent fault diagnosis of rotating machinery, Digital Signal Processing, 14, 203-217.

5. Chen Q., Tombinson G.R. (1994), A new type of time series model for the identification of non-linear dynamical systems, Mechanical System and Signal Processing, $\mathbf{8}, 5,531-549$.

6. Hermans L., Van der Auweraer H., Abdelghani M. (1997), A critical evaluation of modal parameters extraction schemes for output only data, Proceedings of the International Modal Analysis Conference Japan, pp. 682-688.

7. Hermans L., Van der Auweraer H., Coppens P., Mathieu L. (1996), Modal parameter extraction from in-operation data, 15th IMAC Proceedings, Orlando, Floryda, pp. 531-539.

8. Heylen W., Lammes S., Sas P. (1993), Modal Analysis Theory and Testing, Katholike Universiteit Leuven, Belgium.

9. Kurowski P. (2007), Modal-model applications for large energetic machines, Key Engineering Materials, 347, 221-226.
10. ŁĄCZKOWski R. (1974), Vibrations of elements of steam turbines [in Polish], Wydawnictwa NaukowoTechniczne, Warsaw, Poland.

11. OrŁowski Z. (2001), Diagnosis in the long term operation of the steam turbine [in Polish], Wydawnictwo Naukowo-Techniczne, Warsaw, Poland.

12. Peeters B., De Roeck G. (2001), Stochastic system identification for Operational Modal Analysis: a review, Journal of Dynamic Systems, Measurement and Control, 123, 659-667.

13. PiŁAT A. (2002), Steering of magnetic levitation systems [in Polish: Sterowanie uktadami magnetycznej lewitacji], Ph.D. Thesis, Katedra Automatyki AGHUST.

14. PiŁAT A. (2004), FEMLab software applied to active magnetic bearing analysis, International Journal of Applied Mathematics and Computer Science, 14, 4, 497501.

15. Pintelton R., Schoukens J. (2001), System Identification: A frequency domain approach, IEEE Press.

16. Smit W.G., Heyns P.S. (2002), Fan blade damage detection using on-line vibration monitoring, R\&D Journal, 18, 3, 77-90.

17. Stoisser C.M., Audebert S. (2008), A comprehensive theoretical numerical and experimental approach for crack detection in power plant rotating machinery, Mechanical Systems and Signal Processing, 22, 818844.

18. Uhl T., Bogacz M. (2004), Real time modal analysis and its application for damage detection, Proceedings of ISMA Conference, pp. 1066-1076.

19. Uhl T., Lisowski W., Kurowski P. (2001), In-operation modal analysis and its applications, Wydawnictwo Katedry Robotyki i Dynamiki Maszyn AGH-UST, Cracow, Poland. 